\title{
Génesis, desarrollo, status y futuro del proyecto de armonización de los principios y las normas del Proceso Civil Transnacional $\left({ }^{*}\right)\left({ }^{* *}\right)$
}

Aníbal Quiroga León

\begin{abstract}
A Frédérique Mestre, jurista francesa, con amistad y gratitud.
Y también a mi colega y compañera de beca Prof. Ana Djoric, de Serbia, $y$ a todos los funcionarios, empleados, colaboradores y becarios del UNIDROIT quienes, de alguna u otra manera, sin saberlo,
\end{abstract} forman parte de este texto.

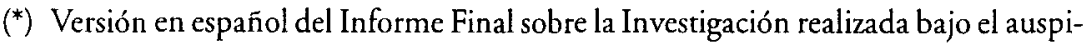
cio de la Beca concedida por el Programa de becas del UNIDROIT, Roma, Italia; del lero. de abril al 02 de julio del 2002; gracias a las amables referencias del Sr. Dr. Héctor FixZamudio, Investigador Emérito del Instituto de Investigaciones Jurídicas de la UNAM, México. Ex Presidente de la Corte Interamericana de Derechos Humanos. Doctor Honoris Causa por la Pontificia Universidad Católica del Perú. Presidente del Instituto Iberoamericano de Derecho Constitucional. Miembro del Instituto Internacional de Derecho Procesal; del Instituto de Derecho Agrario Internacional y Comparado; del Instituto Español de Derecho Procesal; del Instituto Internacional de los Derechos Humanos de Estrasburgo y de la Academia Mexicana de Legislación y Jurisprudencia; y del Dr. Domingo García Belaunde, Profesor Principal de la Facultad de Derecho de la Pontificia Universidad Católica del Perú, Doctor en Derecho por la Universidad Nacional Mayor de San Marcos, Lima. Perú. Presidente de la Asociación Peruana de Derecho Constitucional. Directivo y fundador del Instituto Iberoamericano de Derecho Constitucional. Miembro de la Comisión de Bases de la Reforma Constitucional peruana. Miembro de la Academia Peruana de Derecho, de la Asociación Argentina de Derecho Constitucional, de la Asociación Venezolana de Derecho Constitucional, de la Academia Nacional de Derecho y Ciencias Sociales de Córdoba, Argentina. Sin embargo, las opiniones y conceptos expresados en el presente trabajo son de exclusiva responsabilidad del autor y no comprometen en forma alguna la posición institucional del UNIDROIT.

$\left.{ }^{(* *}\right)$ Investigación que se ha podido realizar gracias, además, al invalorable apoyo presupuestario conferido por Corporación Aceros Arequipa S.A., así como de colaboraciones de amigos que han preferido mantenerse en reserva, Empresa y amigos a los que el autor expresa su personal reconocimiento. 
«... a un hombre se le cayeron tres monedas, y otro las encontró. Ambos fueron ante el juez y los dos insistían en que no les correspondía quedarse con el dinero. El que dejó caer las monedas, explicó que no merecía recuperarlas porque la pérdida se debía a su propia negligencia. El que las encontró argumentó que no podía quedarse con ellas, por que no le pertenecían originalmente.

Después de escuchar a las partes, el juez sacó otras tres monedas de su propio bolsillo y las agregó a las otras, luego dividió las seis entre los tres. Al final dijo: el que dejó caer las monedas, y que tenía tres al principio, ahora tiene dos; el que encontró tres monedas, también tiene dos; yo tenía tres monedas en mi bolsillo, pero ahora tengo dos. Cada uno de nosotros perdió una moneda. Este es mi Fallo».

Decisión judicial del período feudal EDO (1600-868)'

\section{Presentación}

Dice el viejo refrán castellano que es de persona bien nacida el ser agradecida. Por ello, resulta imperativo en primer lugar expresar gratitud al UNIDROIT por haber otorgado la Beca de Investigación que ha permitido trabajar durante tres meses en su sede en Roma, Italia, y con ello haber hecho posible el avance y desarrollo de la investigación que hoy, de modo preliminar, da lugar a la publicación del presente trabajo.

El esfuerzo por lograr normas uniformes en los procedimientos judiciales de nuestra era, y su actual respuesta en el Proyecto de Principios y Normas (o Reglas) Transnacionales del Proceso Civil constituyen -sin duda alguna- una esperanza del presente y un reto de futuro; reto en aras de estar a la par con el inexorable proceso de globalización y la unificación de los sistemas jurídicos; y esperanza de dotar a los diversos países -y muchas veces ya no tan «diversos»-; esto es, a la comunidad internacional, de mejores condiciones e instrumentos para la consecución de la justicia, de reglas justas, uniformes y predecibles para las diversas administraciones de justicia, de normas homologadas para la diversa solución de los conflictos individuales que al interior de una sociedad siempre se habrán de presentar como parte consustancial del ser humano y de su convivencia grupal,

1 Tomado de Lorenzo Zolezzi, Relevancia social del Juez Civil; Ponencia ILANUD, San José, 1987. 
y que al haber intenso intercambio comercial, económico, cultural y social, extiende la génesis y solución de tales conflictos a los justiciables de una y otra comunidad nacional, de uno y otro lado de la frontera, de uno y otro lado de los mares.

Tuve el honor de ser invitado a finales de 1999 a incorporarme en el Proyecto de Principios y Reglas del Proceso Civil Transnacional, mezcla de reto e ilusión, calificado por algunos de utopía o irrealizable, lo que se materializó como International Consultant por el Perú desde marzo del 2000, gracias a la gentil invitación que en su momento me formularan precisamente los Profs. Geoffrey C. Hazard, Jr., co-Reporter y Antonio Gidi, Associate Reporter, del American Law Institute ${ }^{2}$.

La experiencia académica y profesional de los operadores jurídicos, y en especial los que nos dedicamos al estudio y práctica del litigio civil y comercial, nos ha permitido reflexionar en más de una oportunidad de la necesidad de uniformizar las reglas que se apliquen en las controversias jurídicas que vinculen a entidades privadas y cuyos efectos incidan en diferentes países.

Hoy el UNIDROIT, dentro de su desarrollo institucional y prestigio internacional ${ }^{3}$, ha posibilitado un período de investigación con el focus en esta materia, precisamente, y la que se desarrolló bajo la conducción y visión de Frédérique Mestre, prestigiosa jurista francesa, y quien como infatigable Directora del Programa de Becas del UNIDROIT, ha hecho realidad esta posibilidad que abrirá las puertas de esta temática al espacio latinoamericano.

2 Como consecuencia de esta fructífera relación, en octubre del 2000 fui invitado a asistir al Seminario Internacional «Vers un procés civil universel? Les regles transnationales de procédure civile de l'American Law Institute", organizado por la Universidad PanthéonAssas (París II) y el American Law Institute, en París, habiéndose publicado el texto Vers un procés civil universel? Les regles transnationales de procédure civile de l'American Law Institute, edición hecha bajo la dirección del Prof. Philippe Fouchard.

3 El UNIDROIT es una organización internacional intergubernamental independiente, con sede en Roma, creada en 1926 y reconstituido en 1940 sobre la base del Estatuto de UNIDROIT, y tiene por principal finalidad la reflexión y el estudio de las vías de armonización del derecho civil y comercial -en sus diversas manifestaciones- entre los Estados -sin excepción, sean o no miembros del Estatuto UNIDROIT, como el caso del Perú que no lo es aún-y entre los grupos de Estados, así como la preparación gradual de materiales y proyectos para la adopción de normas comunes, principios y tratados internacionales sobre esta materia. 
En este caso, quizás el reto más importante, y el gran escollo también, radica en tener que vincular de modo necesario a instituciones procesales nacidas en los dos grandes sistemas jurídicos. A saber, las pertenecientes al Common Law y al Civil Law .

La dinámica actual del mundo en que vivimos, la universalización a la que apuntan los nuevos y muy veloces sistemas de información, y las nuevas modalidades de contratación en un cada vez más intenso tráfico internacional y sus nuevas formas económicas, constituyen por sí solos motivos más que suficiente para intentar en un mediano plazo la unificación de la regulación procesal de las controversias civiles y comerciales que surjan como consecuencia inevitable de esta globalización. Esta se manifestará inexorablemente en una globalización del litigio, de la controversia y de la crisis de las relaciones sociales e individuales de las diferentes comunidades nacionales, impulsando la necesidad de creación de iguales soluciones jurídicas a nivel macro, extraterritorial, necesariamente universalizante. Este Proyecto y esfuerzos, dignos de ser intentados, se inscribe precisamente en esa dirección, bajo el axioma de que la fe es la fuente de la creatividad humana.

Es actualmente impensable que las fronteras nacionales sigan siendo al mismo tiempo barreras culturales, sociales o económicas, como las murallas que separaban, para su defensa y autarquía, a las antiguas ciudades. Por ello, la finalidad de este importante proyecto, habida cuenta del desarrollo e incremento de las transacciones comerciales de orden internacional, hacen casi de impostergable necesidad pública que las mismas tengan mecanismos comunes de seguridad y formas procesales acordes con la magnitud de su desarrollo, de manera tal que el sistema jurídico provea a los justiciables de fórmulas simplificadas, expeditivas y comunes de solución de las controversias que se pudieran plantear, con la doble finalidad, parafraseando al insigne maestro uruguayo Eduardo J. Couture, de dar solución fácil, económicamente reducida y rápida a los inevitables conflictos particulares, otorgando al mismo tiempo seguridad y paz a la co-

4 Ver Aníbal Quiroga León, Presentación de la Edición especial de DERECHO PUC, «Proyecto de Normas Transnacionales del Proceso Civil»; Fondo Editorial PUCP del Perú, Lima, diciembre 1998-marzo 1999.

También en: Philippe Fouchard, Vers un procés civil universel? Les regles transnationales de procédure civile de l'American Law Institute, Débats: Aníbal Quiroga León, pp. 29-30; Ed. Pantheon Assas, París 2000. 
munidad internacional en el alcance de las mismas.

Ello, claro está, dentro del cabal respeto de las normas nacionales e internacionales que garantizan un debido proceso legal o tutela jurisdiccional efectiva a los justiciables, precisamente dentro de los estándares internacionales que este universalizante concepto ha desarrollado hasta ahora. Por ello, resulta de trascendental importancia contar con una normatividad uniforme e internacionalmente aceptada que permita que los sistemas de justicia inter e intranacionales funcionen acordes con estas circunstancias como contribuyentes del desarrollo económico y social de las naciones.

En ello, el concurso y apoyo de la Teoría General del Proceso es indispensable a fin de sistematizar, tematizar y explicar los diversos principios y avances, las fuentes mismas de los instrumentos procesales que determine su necesidad y posibilidad de unificación u homologación. Sin temor a exagerar, se podría comparar la génesis y el avance cualitativo de este proyecto con la historia de la ciencia del proceso, cuando en 1868 Oskar von Bülow publicó la obra que marcó el fin del procedimentalismo y dio partida de nacimiento a la era científica del proceso con la Escuela Publicista en Alemania, antecesora de la italiana y española ${ }^{5}$. Precisamente ha sido Ibañez de Aldecoa ${ }^{6}$ quien con acierto ha señalado que:

«Le cabe al Derecho Procesal el privilegio de haber motivado, en los últimos años, la inquietud de la investigación, a cuyo impulso los procesalistas se han movilizado hacia el cumplimiento de una tarea trascendente al asumir la responsabilidad de construir científicamente sus cuestiones, de tematizar y problematizar sus puntos vitales que permanecían ocultos en los sistemas, de presentar el proceso como institución cualificada digna de investigación que tenga suficiente sustantividad y autonomía, y sobre la cual se ha de construir una especialización jurídica de firmes y propios contornos».

Hasta ahora, nuestra participación en el presente proyecto, que se ha referido básicamente a su difusión, interpretación, explicación y traduc-

5 Oskar von Bülow, La Teoría de las Excepciones Procesales y los Presupuestos Procesales; (Giesen, 1868) traducción de Miguel Angel Rozas Lichtschein Ed. Jurídicas Europa América, Bs. As. 1964.

6 Alfonso lbáñez de Aldeoca, Meditaciones sobre la cientificidad dogmática del Derecho Procesal. Contraportada. 
ción al español de sus diversas versiones, específicamente en lo referido a los diversos términos legales que se utilizan en América hispana pero que muchas veces quieren decir lo mismo ${ }^{7}$. No ha sido tarea fácil. No solo porque en la doctrina del derecho, y en la Teoría del Derecho también sin duda, hay conceptos sinónimos, instituciones similares y usos locales, muchas veces nuestra propia formación profesional y jurídica nos lleva a pensar que nuestra significación es la única adecuada, o que nuestros localismos deben de imponerse, o que aceptar otro implica una suerte de despersonalización jurídico-judicial. Nada más opuesto, precisamente, a una Teoría General que pretende ser, globalizante en el arte del juzgamiento humano, tan común como la vida, el aire, el agua o la convivencia pacífica en democracia.

También hemos participado, en el pasado reciente y en colaboración con el American Law Institute con la difusión del último Proyecto de Normas Transnacionales a través de la Revista DERECHO PUC No. 52, órgano oficial de difusión académica la Facultad de Derecho de la Pontificia Universidad Católica del Perú, y de la cual soy su Editor General. En un trabajo conjunto con el Prof. Antonio Gidi, y gracias al apoyo del American Law Institute logramos editar con tal fin una edición especial de una separata de nuestro $\mathrm{N}^{\circ} 52^{8}$, donde se ha incluido las versiones en inglés, español y portugués de la versión inglesa del Discussion Draft del 1 de abril de 1999 del proyecto, con el afán de poder difundirlo en las comunidades hispano y luso hablantes, tanto de América como de Europa e incluso África.

América Latina tiene hoy un gran reto, lograr -a la par de la unificación de sus mercados, sus economías y de sus políticas- unificar su legislación procesal, su justicia, aquella vital que tanto reclaman sus pueblos; y este proyecto se inició con la elaboración del Código Procesal Civil Modelo para Latinoamérica, y actualmente se viene desarrollando un proyecto similar en el campo penal. Cabe señalar, que nuestras raíces legislativas, la unidad idiomática y sobre todo nuestra tradición jurídica nos permite añorar la ansiada unificación en materia procesal'. Este anhelo y reto tra-

7 Aníbal Quiroga León, Op. cit.

8 Ibídem.

$9 \mathrm{Al}$ autor de la presente Ponencia correspondió, en este contexto, en el último VII Congreso Iberoamericano de Derecho Constitucional, en febrero del 2002, en México D.F., sobre la base de esta experiencia acumulada, la propuesta aun singular de iniciar y acometer el estudio y redacción de un proyecto de Código Procesal Constitucional Modelo para Iberoamérica. 
zado por las diversas instituciones que agrupan a los investigadores del Derecho Procesal en todas sus ramas, podría verse robustecido con la difusión de los Principios y Reglas Transnacionales del Proceso Civil. No es ajeno al pensamiento latinoamericano la búsqueda de la unificación legislativa en el campo procesal, y ello puede servir de sustento para una mayor difusión de este importante proyecto.

¿Por qué pensar en una legislación procesal transnacional unificada en materia civil y comercial? Esta interrogante no resulta ajena tampoco a la realidad latinoamericana. Baste ver para ello que la legislación procesal federal y provincial argentina en materia civil y comercial van siempre unidas. Si bien es cierto, ello no ha sido así adoptado por otros tantos países latinoamericanos, no podemos negar aquellos que ejercemos en el campo del litigio que una y otra rama del proceso va casi siempre unidas. Resulta casi impensable pensar que el proceso civil pueda desvincularse del proceso mercantil; para ello basta ver que los negocios jurídicos otrora estudiados por el Derecho Civil cada vez se ven más influenciados del derecho comercial y si damos un paso más allá, veremos como el derecho comercial cada día se ve más involucrado con el derecho internacional privado, pues las transacciones civiles comerciales que hasta hace cincuenta años se circunscribían únicamente al ámbito local, hoy pueden traspasar fronteras en menos de un minuto a través de las transacciones electrónicas o digitales, que han convertido al derecho mercantil, en un derecho de orden internacional. Este avance en las transacciones, hoy electrónicas, requiere que se desarrolle (en el menor plazo posible) un soporte procesal elemental y unificado, donde no solamente prevalezcan los regionalismos (véase en este sentido las leyes de la Comunidad Europea, que poco a poco irán sustituyendo a las leyes nacionales), sino donde se aborde la difícil pero necesaria tarea de unificar las reglas procesales que deberán implementarse y prevalecer ante este avance "transnacional» del derecho civil y mercantil.

En resumen, las condiciones están dadas para poder desarrollar, difundir y estudiar con ahínco este importante Proyecto de Unificación de las Reglas (o Normas) Transnacionales del Proceso Civil. Latinoamérica tiene experiencia respecto a la preparación y utilización de proyectos modelo o Códigos Base, tiene también a su favor el hecho de contar con el mismo idioma y una sola tradición jurídica. En consecuencia, mayores facilidades para poder ingresar en este ambicioso proyecto no podemos pedir, solo requerimos del empeño y trabajo en la difusión de estas normas. Ello 
nos permitirá en un futuro sino cercano, por lo menos mediano, obtener en primer orden la unificación de las reglas elementales que deben prevalecer en todo proceso de orden civil-mercantil, y con posterioridad a ello incorporarnos plenamente a la regulación transnacional que con este proyecto se pretende lograr.

\section{Sobre la teoría general del proceso}

El Derecho Procesal ha recibido, generalmente, una valoración secundaria dentro de los diversos ordenamientos jurídicos, más aun a diferencia de otras disciplinas jurídicas, muchas veces ni siquiera se han seguido las modernas corrientes doctrinarias ni se han conocido los avances científicos en material del proceso.

Así, es muy poco lo que se admite -y menos aún lo que se conocesobre la dogmática jurídica del proceso y su Teoría General, sus instituciones y la cientificidad de sus postulantes, tal como se reconoce en la actualidad y, sobre todo, la capital importancia que ello tiene dentro del ordenamiento jurídico, tanto así que trasciende su propio límite institucional para alcanzar terrenos más alejados llegando, incluso, a los constitucionales.

Si partimos de reconocer que el Derecho no es un simple sistema de reglas estáticas y aprehensibles que regulan a la sociedad a través de la vigencia de sus normas, ya sea voluntaria o coercitivamente, con la mediación del organo jurisdiccional, sino que, como lo sostiene Latorre ${ }^{10}$, es una ciencia de vigencia social cuyas reglas jurídicas deben su complejidad a la naturaleza misma de la sociedad; comprenderemos que el atrofiado desarrollo de uno de sus pilares resultará clamoroso para impedir la consecución de la justicia como fin mediato y la paz social en la solución de los conflictos intersubjetivos como fin inmediato.

$Y$ es que la justicia, al decir de Devis Echeandia" ${ }^{11}$, como noción abstracta es inmutable; pero la manera de lograrla en la práctica, difícil y esquiva, es necesariamente cambiable porque debe ajustarse a la perma-

10 Angel Latorre, Introducción del Derecho, Ed. Ariel, Barcelona, 1969; pp. 8082.

11 Hernando Devis Echeandía, «IV Jornadas Latinoamericanas de Derecho Procesal” En: Revista de Derecho Español y Americano No 17; Año XII, II Epoca, Jul-Sept., Inst. de Cultura Hispánica, 1996, p. 177. 
nente evolución del medio social y de la persona humana misma. En cada período histórico ha existido un diferente concepto de justicia y un especial procedimiento para adoptarla; sin que antes, ni ahora se haya alcanzado perfección, ni tal vez se la logre nunca, ni siquiera esa relativa e incompleta que suele satisfacer al hombre y que es la única que está a su alcance.

Esa es la razón de ser del Derecho Procesal y el fundamento del proceso. Por eso, sólo a través de su adecuado desarrollo se han de perfilar las adecuadas relaciones de justicia, y sólo a través de ello se puede pretender un coherente desarrollo social y humano. Por esto, partiendo desde el principio, se debe reconocer que corresponde al ordenamiento jurídico una adecuada regulación procesal, y que esta regulación compete, a su vez, a todos los estamentos del derecho. Es ilusorio pretender el desarrollo de una ciencia jurídica nacional sin el avance coordinado y reciprocante de todas las instituciones que constituyen sus pilares. El Derecho Procesal es un importante sostén para la realidad, vigente y efectividad de las relaciones subjetivas que norman la convivencia social y la relación entre el Estado y los justiciables.

La importancia del proceso aparece graficada en su principal fundamento: la sustracción al hombre la posibilidad de dar solución privativa a sus conflictos particulares. Por ello, Aragoneses ${ }^{12}$ sostiene que, en su ausencia, el hombre involucraría a sus orígenes en que la autotutela o autodefensa definía el primer impuso del sentimiento del derecho contra la injusticia: la acción violenta, la imposición de la fuerza antes que las razones, el origen de la defensa privada y de la venganza, esa justicia salvaje que se ha superado, precisamente, con la vigencia del Estado de Derecho.

Ya en los preliminares estudios del Derecho Procesal como ciencia esto era advertido así, tal como lo expresara el Conde de la Cañada ${ }^{13}$, cuando expresaba que:

"Los hombres, que en su estado primitivo natural no reconocían superior que los defendiese de insultos, opresiones y violencias, estaban por consiguiente autorizados para haberlo por sí propios: la experiencia les hizo entender los graves daños a que conducían estos me-

12 Pedro Aragoneses Alonso, Proceso y Derecho Procesal; Aguilar, Madrid, 1960, p. 27.

13 Cit. por Jesús González Pérez, El Derecho a la Tutela Jurisdiccional; Ed. Civitas, S.A.; Madrid, 1984, p. 19. 
dios, pues o no podían defenderse por sí mismos, o excediendo los justos límites para conservarse, excitaban turbaciones, a que eran consiguientes mayores desavenencias, injurias y muertes; y consultando otros medios que mejorasen la seguridad de sus personas sin los riesgos anteriormente indicados, acordaron unirse en sociedades y confiar su defensa y la de todos sus derechos a una persona que mirándolos con imparcialidad les distribuyese sus derechos y los conservase en justicia y paz."

Por eso, acota el propio González Pérez ${ }^{14}$, sólo impidiendo el ejercicio de la fuerza privada como modo de satisfacer las pretensiones y el reconocimiento de los derechos, podrá asegurarse el imperio de la justicia. De un caos en que prevalecía la ley del más fuerte se pasó a un orden jurídico en el que prevalece el criterio de un sujeto imparcial, sustituyéndose la acción directa frente al adversario por la acción dirigida hacia el Estado, a fin que los órganos especialmente instituidos para ello acogieran y actuaran las pretensiones deducidas por un sujeto frente a otro. La historia de la sustitución de la autotutela o autodefensa por el proceso ha sido, en definitiva, la historia del desarrollo social del hombre.

Pero resulta necesario también tener en cuenta -para evitar un lineal desarrollo conceptual- que como la historia de la humanidad no ha sido en modo alguno un progresivo y constante aumento de las virtudes morales del hombre, tampoco ha sido el de una progresiva reducción de la autodefensa en beneficio del proceso; sino que a períodos en que esto ha sucedido así, han sucedido otros en que han aparecido notorias manifestaciones de autodefensa que parecían definitivamente abandonadas. Esto toca directamente a los avatares de nuestro mundo contemporáneo $y$, más cercanamente, a nuestra sociedad nacional severamente amenazada por la violencia. En nuestro mundo de hoy, la violencia se presenta en términos más virulentos y generalizados que nunca, llegándose a hablar inclusive de la actualidad de la venganza ${ }^{15}$ para reflejar el resurgimiento de la autodefensa en sus formas más rencorosas y arbitrarias. ¿Cuáles son, acaso, las causas de este resurgimiento defensivo? Muchas y de diversas

14 Op. cit., p. 20.

15 Título del libro de Ruiz Funez; Bs. As., 1944; Cit. por Niceto Alcalá Zamora y Castillo, Proceso, Autocomposición y Autodefensa; Imp. Universitaria, 2da. Ed., México, 1972; p. 64; Op. cit., p. 21 y Cit. 4. 
índole dice González Pérez ${ }^{16}$, pero quizás -y sin quizás tal vez- el primer lugar la desconfianza, y hasta el desprecio, del ciudadano hacia la justicia que ofrece el Estado. Los derechos ciudadanos, sobre todo los fundamentales, se ven severamente conculcados cuando el respeto hacia la autoridad del Estado como dirimente de los conflictos sociales e intersubjetivos es desconocida; por más fuertes y aún brutales que puedan ser los elementos coercitivos que el Estado pueda emplear, se verán desbordados por la desesperada búsqueda de justicia. De aquí se concluye la importancia del proceso como instrumento del Debido Proceso o una Efectiva Tutela Judicial, -definidos como la posibilidad de que todo aquél que tenga un derecho en disputa pueda acudir ante el órgano jurisdiccional para que su controversia sea dirimida con certeza, esto es, haciendo efectivo el derecho material del caso concreto y haciendo a su vez realidad el ideal de justicia inherente a ese derecho aplicable a dicho caso concreto.

A partir de esto, se puede inferir que una defectuosa regulación procesal incidirá más allá del aspecto meramente jurídico hasta llegar a las propias relaciones sociales, como lo señala el tratadista italiano Piero Calamandrei ${ }^{17}$, al determinar que la norma jurídica procesal es la regla técnica tutelada por el Estado e investida de autoridad con la que se accede a la vida pacífica de la sociedad y que constituye la realización de la función más solemne y más elevada del Estado: la justicia, que es el fundamentum_republicae.

Es esto lo que explica otro de los grandes tratadistas italianos, Mauro Cappelletti ${ }^{18}$, al señalar que el Derecho Procesal es contemplado como un fenómeno ligado a las extraordinarias conmociones que se han sufrido en la historia del hombre, especialmente en la contemporánea: la economía y, por consiguiente en las estructuras políticas, económicas y sociales, como también en las concepciones éticas y gnoseológicas. Así, el fenómeno procesal es contemplado hoy en su inserción en un mundo que, como el de hoy, está abriéndose necesaria y penosamente paso a nuevas formas de convivencia en el abandono -de particularismo anacrónico- y en el intento -tal vez el intento extremo de la humanidad- de crear instrumentos jurídicos idóneos para superar el riesgo de la catástrofe inmanente en

16 Jesús González Pérez, Op. cit., p. 21.

17 Piero Calamandrei, Proceso y Democracia; Eds. Jcas. Europa América; Buenos Aires, 1960, p. 32.

18 Mauro Cappelletri, Proceso, Ideologías y Sociedad; Eds. Jcas. Europa-América, Buenos Aires, 1974, p. X. 
nuestra época termonuclear, a un tiempo fascinante y terrífica. Por último, la perspectiva constitucional es la de una ansiosa búsqueda de valores sociales e individuales de justicia y libertad ${ }^{19}$, valores nuevos pero superiores, búsqueda en suma de un punto de arribada -al menos provisional- en la tempestuosa corriente de las transformaciones que se están operando.

Ahora bien, el progreso del Derecho Procesal ha supuesto que su análisis no solo ingrese a los campos del Derecho constitucional, hoy, podemos ver como el Derecho procesal ha cruzado las fronteras del derecho nacional, y el hombre en la vorágine de cambios que vive actualmente ha ingresado ya al campo del Derecho Procesal Internacional o Transnacional.

El Derecho procesal es uno solo, y una sola es la Teoría General del Proceso, partiendo de esta premisa, nos toca en este informe analizar cómo el Derecho procesal ha ido cobrando vigencia dentro del Derecho internacional público y privado, y cómo esperamos que esta vigencia logre finalmente constituirse en la armonización y unificación de determinadas normas que son esenciales para el desarrollo de un Derecho procesal transnacional.

En la línea de lo expuesto precedentemente, mención aparte merece el Derecho procesal penal internacional, que ha logrado finalmente el establecimiento de una Corte Penal Internacional. Claro está, la necesidad de la sociedad de perseguir de modo globalizado el juzgamiento de los denominados delitos contra la humanidad ha determinado que esta rama del Derecho procesal transnacional haya conllevado un desarrollo más dinámico; pero ello no puede ni debe significar que en el campo del Derecho civil y comercial perdamos de vista el importante proyecto que ha iniciado el American Law Institute y UNIDROIT con la finalidad de lograr dentro de algún tiempo la unificación de ciertas normas que, entendemos, deben estar presentes en toda legislación procesal nacional.

Así pues, hoy el Derecho procesal civil nos invita no solamente a analizarlo desde la perspectiva de los derechos nacionales, sino también desde la perspectiva del Derecho internacional; y sino baste ver para ello que en América Latina el Código Procesal Civil Tipo para Iberoamérica, ha cobrado tal vigencia, que nuestras actuales legislaciones procesales civiles,

19 Por ello Proceso y justicia son conceptos íntimamente ligados, como lo son justicia y libertad. Uno no existe sino en función del otro, y ésta no podría realizarse sino es a través de aquél: "Miglior giustizia attraverso maggior libertá». Piero Calamandrei, Processo e Democrazia. Prefazione; CEDAM, Padova, 1954. 
puntos más, puntos menos han tratado de seguir dicho modelo, en aras de la unificación de la legislación procesal civil, partiendo siempre desde la premisa que las instituciones del Derecho Procesal son únicas y por ello pueden ser utilizadas y recreadas por las legislaciones internas sin que ello signifique una modificación de sus fundamentos.

\section{Génesis del proyecto}

El Proyecto de Principios y Reglas del Proceso Civil Transnacional data de 1995, cuando el American Law Institute inicia la preparación de este proyecto. Desde el 2000 cuenta con el apoyo de UNIDROIT, que ha permitido, entre otros importantes aspectos, llegar a un importante número de Estados que forman parte de este organismo internacional. La conjunción de ambas instituciones tiene por finalidad poder expandir este proyecto a diversos Estados del orbe, y que su debate, análisis y modificaciones permanentes, posibiliten que se obtenga una mayor difusión internacional del objetivo principal del proyecto: la armonización y unificación de la legislación procesal civil y comercial.

La pregunta de rigor en este punto no es otra sino la de ¿Por qué es importante la unificación del Derecho Procesal Civil? La respuesta la encontramos principalmente en un hecho constatable por todos nosotros: la dinámica actual de las transacciones civiles-comerciales hacen necesario para los operadores jurídicos contar con principios básicos y reglas generales en aras de la obtención de la seguridad jurídica que todo inversionista extranjero exige como requisito indispensable, de modo previo, al desembolso patrimonial que su inversión requiera.

En Latinoamérica vivimos hoy una época donde la inversión extranjera constituye la fuente de la mayor parte de los ingresos nacionales. Ahora bien, uno de los frenos que dicha inversión extranjera encuentra es el temor de enfrentarse, en un país diferente, con una lengua también diferente, a una realidad jurídica que puede ser muchas veces harto confusa para el inversionista norteamericano o europeo. Esta confusión está plasmada en el sinfín de normas sustantivas que regulan los fundamentos esenciales de la protección patrimonial, partiendo claro está en las Constituciones de cada uno de los Estados americanos. Ahora bien, si a la confusión e inseguridad que puede generar esta diversidad de los ordenamientos jurídicos, aunamos una desconfianza casi generalizada respecto de las activi- 
dades de los diversos poderes judiciales de cada uno de los Estados latinoamericanos, y para ello una inseguridad, también latente, en el plano de la legislación procesal que regula las actividades comerciales y civiles, tendremos como resultado inmediato: la disminución o erradicación de la inversión extranjera, en territorios donde esta es fundamental. Creemos que resulta también pertinente señalar, que el reciente nacimiento y desarrollo de los países de Europa oriental constituye una alternativa ciertamente interesante para el inversionista americano, asiático o de la unión curopea; y si dichos nuevos Estados tienen como objetivo el asimilar rápidamente los fundamentos esenciales de un Estado de Derecho, y la implementación de una economía de mercado, donde se privilegie las relaciones comerciales; la respuesta del inversionista extranjero será preferir dichos estados europeo-orientales, en vez de optar por Latinoamérica.

He aquí uno de los fundamentos principales del proyecto de Principios y Normas del Proceso Civil Transnacional, pretender no otra cosa que el extranjero que acuda a un ordenamiento jurídico foráneo pueda encontrar cierta seguridad en el hecho que cualquier controversia que se derive de sus relaciones jurídico-económicas sea tramitada conforme a unas reglas conocidas para este. Es tal vez este el más importante de los motivos por el cual Latinoamérica no puede permitirse el lujo de apartarse del Proyecto de Principios y Reglas del Proceso Civil Transnacional.

Hemos dicho en la primera parte del presente informe que el Derecho procesal es uno solo, y por ende sus principios e instituciones también lo son. Ahora bien, lo antes expuesto no supone que esta unicidad del Derecho Procesal no se encuentre afectada por los usos, costumbres, y antecedentes jurídicos que cada sistema legal trae consigo desde antaño.

Solo a modo de ejemplo podríamos señalar que, a pesar de nuestros antecedentes y lengua común, y a pesar de la intención de uniformizar la Legislación Procesal Civil Iberoamericana, vamos a encontrar diferencias importantes en el tratamiento procesal civil que determinadas instituciones reciben en Iberoamérica.

Importa para nuestra Investigación la realidad sudamericana, pues es la realidad en la que desarrollamos nuestra actividad académica y profesional, y porque creemos que se debe fomentar en esta parte del continente un adecuado estudio del proyecto en mención.

Un punto importante a analizar dentro de la génesis del Proyecto de Principios y Reglas del Proceso Civil Transnacional es la dificultad que subyace a la presencia de dos sistemas legales básicos: el common law y del 
civil law. Esta coexistencia a nivel internacional ha determinado que este proyecto deba proseguirse a la luz de las instituciones y principios de cada uno de estos sistemas, y que finalmente podamos rescatar del Derecho procesal aquellas instituciones elementales, esto es, instituciones que se encuentran presentes en ambos sistemas legales, y que podemos denominar como los conceptos básicos del derecho procesal.

El segundo de los problemas, creemos, dentro de la génesis del proyecto ha sido la traducción de estos principios y reglas a diversos idiomas, con la finalidad de llegar a casi todos los confines del mundo. Solo a modo de ejemplo, y en aras de apreciar la dificultad de la adecuación idiomática ciertamente requerida en esta tarea, podemos señalar que en el caso de la traducción al español, se han requerido más de un especialista que adecue la traducción española a los modismos y términos que en los diversos países iberoamericanos se utilizan. En consecuencia, creemos que ha sido muy importante la inclusión al proyecto de miembros, consejeros e investigadores de más de un país iberoamericano, puesto que ello podrá dar mayor riqueza al contenido de la traducción al español, pues finalmente lo que creemos se debería obtener en la traducción final de los Principios y Reglas es una versión comprensible y aplicable de modo general en todos los países de habla hispana, donde finalmente se tenga como punto de elemental consenso la definición de las diversas instituciones del derecho procesal que son parte del proyecto mismo.

\section{Desarrollo y evolución}

Respecto del desarrollo del Derecho procesal internacional en América Latina cabe citar a Maekelt ${ }^{20}$ quien señala lo siguiente:

"No queda atrás el campo de Derecho procesal internacional con especial énfasis en la cooperación judicial.

Las Convenciones aprobadas en todas las conferencias interamericanas salvo la quinta, testimonian esta afirmación: exhortos o cartas rogatorias (1975) y su protocolo (1979); recepción de pruebas en el extranjero (1975),

20 Tatiana Maekelt, «El desarrollo del Derecho internacional privado en las Américas." En: http://www.oas.org/juridico/spanish/tatiana_maekelt.htm 
y su protocolo (1984); régimen legal de poderes para ser utilizados en el extranjero (1975); eficacia extraterritorial de las sentencias y laudos arbitrales extranjeros (1979); cumplimiento de medidas cautelares (1979); prueba e información acerca del derecho extranjero (1979) y competencia en la esfera internacional para la eficacia extraterritorial de las sentencias extranjeras (1984).

Las convenciones llamadas "procesales" regulan casi todos los grandes temas de Derecho procesal internacional. Faltaría un ámbito cuya codificación está relacionada con muchas dificultades: la llamada jurisdicción directa, es decir, competencia procesal internacional. Lograr acuerdo de los Estados miembros resulta sumamente difícil, por ello este tema nunca ha sido incluido en la programación de las conferencias especializadas.»

América Latina es aún un continente joven, en desarrollo, si se compara en relación con la Europa continental, y que desde un inicio buscó unificarse, para ello baste ver que desde el nacimiento de las repúblicas latinoamericanas hubo una tendencia a la cohesión de los diversos países independizados. El sueño de Bolívar de lograr finalmente una sola nación latinoamericana no ha podido verse realizado, no obstante ello, ese pensamiento se encuentra latente, y es por ello que a inicios del siglo XXI encontramos que Latinoamérica no está conformada por países totalmente individuales, dicho en otras palabras, Estados recelosos de unificarse con otros en ciertas materias.

Convenios interamericanos tales como la propia creación de la Organización de Estados Americanos, y otros como el NAFTA, el Pacto Andino, el MERCOSUR (que lamentablemente puede verse afectado por la gran crisis que vive hoy la Argentina) o la ODECA (Organización de Estados Centroamericanos) constituyen los instrumentos internacionales que plasman el anhelo latinoamericano de lograr unificarse, por lo menos en ciertas materias.

Desafortunadamente, la suma de microregionalismos estatales y culturales ha impedido que se cree una gran comunidad de naciones latinoamericanas donde se tenga por finalidad establecer un ordenamiento jurídico uniforme en determinados aspectos. Si bien es cierto la Organización de Estados Americanos ha buscado una cierta unificación de criterios en ciertos aspectos de la vida en sociedad, no se ha logrado grandes avances de unificación que podemos apreciar en la Comunidad Europea. Ello, no obstante el privilegio que tenemos en Latinoamérica de contar básicamente con un solo idioma y un ancestro bastante más homogéneo, cier- 
tamente con diversas acepciones, pero a fin de cuentas un solo idioma que nos permite viajar desde Cabo de Hornos hasta México, sin perder en ello la posibilidad de utilizar la lengua de Cervantes. Asimismo, tampoco debiera ser un gran escollo para la unificación de nuestra legislación procesal la coexistencia de los sistemas del common law y del civil law, puesto que en Latinoamérica resulta preponderante este último sistema parte de nuestra herencia colonial.

Hispanoamérica está viviendo desde la década del sesenta del siglo XX una renovación en el campo del Derecho Procesal. Históricamente nuestros países tienen como sistema procesal matriz la Ley de Enjuiciamientos Española de 1851. Con el inicio del siglo pasado se dieron sendas modificaciones en la legislación procesal civil latinoamericana. Por ejemplo, en el Perú se promulgó en 1912 el Código de Procedimientos Civiles, vigente casi plenamente hasta la década del 70 cuando sufrió una serie de modificaciones con la finalidad de adaptarlo a las nuevas tendencias que habían surgido en las décadas anteriores. Nuestro país, pretendió modificar totalmente su legislación procesal desde 1940, sin tener ello éxito hasta 1992, cuando recién entró en vigencia un nuevo Código Procesal Civil. La legislación procesal civil peruana es producto de más de una Comisión Parlamentaria, puesto que durante las diversas etapas tanto democráticas como dictatoriales se pretendió conformar comisiones multisectoriales que tuvieran por finalidad elaborar la tan ansiada y novísima legislación procesal civil. Finalmente, con muchos aciertos y algunos desaciertos, contamos hoy con una legislación procesal civil, que ciertamente requiere de urgente modificación y corrección, pero que en gran parte ha sustituido el antiguo sistema procedimental que imperó en nuestro país.

Ya en el siglo XXI, cuando prácticamente han desaparecido los problemas limítrofes-territoriales entre los países latinoamericanos, o están camino a resolverse algunos de los pocos que quedaron como rezago del siglo que concluyó; es tarea de Latinoamérica lograr su unificación.

Parte del trabajo iniciado para dicha unificación, específicamente en el campo jurídico, que es el que nos toca a nosotros analizar, lo desarrolla el Comité Jurídico Interamericano de la OEA, creado sobre la base de lo previsto en la Carta de la Organización de Estados Americanos:

«El Comité Jurídico Interamericano

Art. $99^{\circ}$ 
El Comité Jurídico Interamericano tiene como finalidad servir de cuerpo consultivo de la Organización en asuntos jurídicos; promover el desarrollo progresivo y la codificación del derecho internacional, y estudiar los problemas jurídicos referentes a la integración de los países en desarrollo del Continente y la posibilidad de uniformar sus legislaciones en cuanto parezca conveniente.»

Sobre la base de la norma internacional antes citada, el Comité Jurídico Interamericano ha realizado sendas conferencias, reuniones y respecto a la materia a la cual hoy se avoca nuestra investigación, ha concluido lo siguiente ${ }^{21}$ :

«IV. Integración económica y libre comercio

Los procesos de integración, presentan desde el punto de vista jurídico, aspectos que deben ser objeto de una atención especial.

El cambio de la realidad internacional, como resultado de la apertura e internacionalización de la economía ha creado la necesidad, entre quienes participan en el intercambio de bienes y servicios, de encontrar vías que garanticen la seguridad jurídica de las transacciones comerciales y en los conflictos que puedan surgir.

En el ámbito mundial el arbitraje comercial ha demostrado ser un instrumento idóneo, ágil y eficaz para suministrar esa seguridad jurídica y resolver las controversias que surgen del tráfico mercantil. Sin embargo, en el marco del continente americano, aunque los gobiernos de los países han hecho esfuerzos para estar acordes con esta nueva tendencia internacional, para lo cual han modernizado sus legislaciones y ratificado convenciones internacionales que reglamentan el arbitraje internacional, tales como las Convenciones de New York y Panamá, ha sido precaria la utilización de este mecanismo como medio alternativo de solución de controversias.

Dada esta necesidad, el Departamento de Cooperación y Difusión Jurídica ha avanzado en el desarrollo e implementación de un programa de capacitación que persigue apoyar a los países en el estudio, análisis y aplicación práctica de este mecanismo.

21 Informe de avance de las actividades del Departamento de Cooperación y Difusión jurídica. Departamento de cooperación y difusión jurídica subsecretaría de asuntos jurídicos secretaría general Organización de los Estados Americanos, Washington D.C., abril, 1999. En: http://www.oas.org/defaultesp.htm 
A. Capacitación e intercambio de información y experiencias sobre arbitraje en Américas Latina

Este proyecto fue realizado en unión de la Comisión Interamericana de Arbitraje Comercial (CIAC) y sus secciones nacionales.

En esta oportunidad participaron, como conferencistas y tutores, 250 destacados abogados y expertos en arbitraje internacional. Los talleres de capacitación se realizaron en Bolivia, Chile, Colombia, Ecuador y Paraguay.

Este programa permitió a los participantes, mediante el desarrollo de las diferentes etapas de un arbitraje internacional, familiarizarse en el manejo de este mecanismo. Brindó la oportunidad de confrontar, analizar y resolver los asuntos, tanto de procedimiento como sustantivos, que surgen de un arbitraje internacional y analizar las posibilidades de su desarrollo en los sistemas jurídicos nacionales. Este proyecto permitió, además, diseñar un programa de difusión del arbitraje internacional, en cada uno de los países participantes.

B. El arbitraje como medio alternativo de solución de controversias y el desarrollo jurídico de las Américas

La importancia de este tema y el respaldo que al mismo han brindado los Centros de Conciliaciones y Arbitraje de las Cámaras de Comercio, la Comisión Interamericana de Arbitraje Comercial (CIAC), la Asociación Americana de Arbitraje (AAA), la Asociación Iberoamericana de Cámaras de Comercio y la Asociación Centroamericana de Cámaras de Comercio, posibilitarán la continuación de las actividades de capacitación iniciadas el año pasado.

En esta nueva fase, se contará con la participación de trece países miembros, quienes participarán en el proyecto, a través de los centros de conciliación y arbitraje de las cámaras de comercio.

Este proyecto representa un nuevo modelo de capacitación más amplio, en relación con el ejecutado en casos anteriores y se desarrollara partiendo de la experiencia que ya ha acumulado el Departamento en esta materia.

Se ha programado la realización de un taller de capacitación regional en Centroamérica y siete talleres adicionales, en distintos países de la región. 
Por medio de estos talleres se capacitarán tanto abogados como académicos, sobre los desarrollos más recientes en la materia. Esto talleres servirán además como un foro que permitirá difundir, entre empresarios y comerciantes, la importancia que tiene el arbitraje internacional como método alternativo en la solución de conflictos.

En la metodología empleada en estos talleres, además de clases magistrales, se utilizan ejercicios prácticos de simulación que promueven un aprendizaje interactivo, que ha demostrado ser más efectivo que los métodos tradicionales de enseñanza.

La preparación del material que se emplea durante estos entrenamientos y el diseño de los talleres, facilitará a los Centros de Conciliación Arbitraje la realización periódica de cursos de capacitación, con características similares a la que aquí se plantea. Con esto no solo se asegura la autosostenibilidad del proyecto, sino además ampliar su alcance a corto y mediano plazo.

Un componente importante de este proyecto es la capacitación que se hará de profesores universitarios, quienes se espera, con el apoyo de los centros de arbitraje y conciliación de las Cámaras de Comercio de sus respectivos países, trabajen en el diseño, formulación e incorporación de cursos sobre esta materia, en sus respectivos centros docentes. La participación de estos profesionales se asegurará mediante el otorgamiento de becas, lo que asegura una selecta y representativa participación de los centros de educación superior.

Otro de los elementos innovadores de este proyecto, es la creación, entre las instituciones participantes de los distintos países, de una Red de Intercambio de Información y de Experiencias. Esta Red facilitara además el diseño y realización de los cursos de capacitación periódica que el Proyecto se propone fomentar, así como el diseño y contenido de las clases que se dictarán en las universidades, como resultado de este esfuerzo.

C. Conferencia sobre resolución de controversias en el mercado mundial

El Departamento de Cooperación y Difusión Jurídica, la Comisión Interamericana de Arbitraje Comercial, conjuntamente con la Sección de Solución de Controversias de la American Bar Association $(A B A)$ y otras organizaciones, co-auspiciaron una conferencia sobre el tema de la Resolución de Controversias en el Mercado Mundial, 
que se llevó a cabo del 2 al 4 de abril de 1998 en Washington, D.C. La conferencia contó con la asistencia de abogados, provenientes de distintos países, quienes acudieron a debatir los diversos aspectos relacionados con los mecanismos de solución de controversias. Entre los temas discutidos, se encuentran los beneficios de incluir cláusulas de arbitraje en contratos internacionales; la importancia de los métodos alternativos de solución de controversias como un método efectivo para reducir la congestión de despachos judiciales; y las pautas de la mediación entre diferentes grupos culturales."

No es ajena a Latinoamérica la investigación y búsqueda de la unificación de la codificación, en aras del progreso de las relaciones civiles-comerciales. Ahora bien, dadas las especiales características de los países latinoamericanos, y aunado a ello los problemas centrales que atraviesan: situación de crisis económica, y búsqueda del respeto de los Derechos Humanos; esta tarea de unificación en materia civil-comercial se encuentra, en parte, rezagada ${ }^{22}$.

«En una primera etapa, que precedió a los movimientos europeos de unificación jurídica continental, los países de América Latina se embarcaron en un ambicioso proyecto de codificación del derecho internacional privado. Una segunda etapa más pragmática, protagonizada por las CIDIP, abandonó la aspiración romántica de la codificación global y se concentró en temas más específicos. Si bien los esfuerzos pioneros y comprensivos de unificación del derecho privado no tuvieron mucho éxito, aquellos realizados por las CIDIPs han culminado hasta la fecha con la aprobación de 21 convenciones interamericanas. Los esfuerzos encaminados a la próxima CIDIP, a realizarse en México en 1994, afirman esta tendencia unificadora hacia una codificación progresiva del derecho internacional privado interamericano.

Los trabajos de las CIDIPs han sido modesta y realísticamente limitados en cuanto a la materia y al espacio. Así, los temas objeto de unificación o armonización no se han extendido más allá de cuestiones relacionadas con los criterios de selección del derecho aplicable y 
la coordinación de mecanismos de cooperación judicial internacional. Aún cuando se prevé la adhesión de estas convenciones por países que no pertenecen a la O.E.A., el ámbito espacial de aceptación de los instrumentos interamericanos no excede en la mayoría de los casos el de América Latina. Este objetivo y lo que ya se ha logrado en su cometido no es desdeñable. Sin embargo, la realidad contemporánea del derecho mercantil internacional exige un replanteo acerca de la conveniencia de mantener una postura regionalista en los esfuerzos de unificación del derecho privado."

No obstante lo antes expuesto, creemos que la investigación y búsqueda de la unificación de las normas en materia procesal civil-comercial, debe seguir siendo parte de la agenda de trabajo latinoamericana, puesto que requerimos, urgentemente, contar con normas claras, textos legales no controvertidos, y reglas que demuestren a la colectividad internacional que la seguridad jurídica es parte de la vida socio económica latinoamericana.

En el contexto de lo señalado precedentemente, ciertamente resulta alentador que el proyecto de ALI-UNIDROIT, sobre los Principios y Reglas del Proceso Civil Transnacional sea difundido en América Latina, puesto que constituirá un aliciente más en la búsqueda interna de la unificación de nuestra codificación civil-patrimonial; que en este caso específico abordará temas que -debido al rezago del Derecho Procesal, al que nos hemos referido en la primera parte del presente informe-, no son cotidianamente investigados por las instituciones u organismos latinoamericanos que fomentan la unificación.

\section{IV.Estado actual}

El actual estado del proyecto de Principios y Reglas del Proceso Civil Transnacional en Latinoamérica es ciertamente alentador, puesto que en la revisión del último borrador (Discusión Draft No 03) del 08 de abril del 2002, que fuera materia de análisis y discusión en las reuniones realizadas en Londres, México, y Roma se ha podido apreciar la mayor colaboración de expertos latinoamericanos.

Encontramos actualmente que este tercer borrador de discusión contiene conceptos más delimitados, hay un notorio avance en su redacción, 
y las definiciones de las instituciones del Derecho procesal pretenden ser más generales.

Lamentablemente aún no contamos con la traducción al español de este tercer proyecto de discusión, la que se viene realizando tanto en España como en diversos países latinoamericanos. Nosotros nos encontramos colaborando con esta traducción en su versión destinada a Sudamérica.

Nuestra colaboración en este Proyecto ha consistido básicamente en lo siguiente:

- Encontrar la forma más adecuada de traducir los Principios y Normas al español, y lograr que la traducción al español contenga una terminología adecuada a nuestros sistemas legales;

- Lograr unificar finalmente una traducción al español que pueda ser utilizada en todos los países de habla hispana;

- Analizar detenidamente las implicancias de las definiciones, términos $e$ instituciones que son tratadas en el proyecto, y proponer una traducción al español compatible con el sentido de lo expuesto en su versión original -en inglés-;

- Aportar nuestra experiencia profesional y académica relativa a nuestra condición de operadores jurídicos en el texto que finalmente constituya la versión definitiva del proyecto; $y$,

- Difundir el estudio y análisis del proyecto a través de las labores de investigación que se desarrollan en la Facultad de Derecho de la Pontificia Universidad Católica del Perú, y de las páginas de DERECHO PUC, Revista Oficial de la Facultad de Derecho de esta casa de Estudios. En este punto cabe señalar que hemos ya contribuido a editar el 20 Borrador de Discusión, en la Edición No $52^{23}$, así como mediante la Edición de una Separata especial que solamente contiene el texto de este borrador de discusión en sus versiones en español y portugués, y además de ello un importante trabajo que sobre esta materia preparó el Prof. Hazard ${ }^{24}$, coautor de las normas; así como la presen-

23 Edición Especial DERECHO PUC, Fondo Ed. PUC del Perú, Lima, 1999

24 Geoffrey C. Hazard, Jr., Civil Litigation without frontiers: harmonization and unification of Procedural Law; (en sus versiones en inglés y español) En: DERECHO PUC No 52, Revista de la Facultad de Derecho de la Pontificia Universidad Católica del Perú; Fondo Ed. PUC del Perú. Lima, 1999.

Ver tambićn: Edición Especial DERECHO PUC; Fondo Ed. PUC del Perú, Lima, 1999 
tación del Prof. Antonio Gidi, Associate ${ }^{25}$ Reporter de dicho proyecto.

Nuestra labor en UNIDROIT nos ha permitido acceder a una valiosa bibliografía con la finalidad de poder ampliar nuestra investigación sobre los fundamentos esenciales en la armonización y uniformización del proceso civil, tomando para ello en consideración que una de las diferencias más importantes que existe entre el civil law y el common law se refiere al sistema procesal que cada uno de estos sistemas prevé.

Durante nuestra estancia en UNIDROIT hemos podido acceder a información de trascendental importancia para con la dinámica que se requiere en la unificación de ambos sistemas procesales. Asimismo, hemos podido participar de las reuniones de ALI-UNIDROIT realizadas en Londres, y en Roma.

\section{Próximas acciones. Evaluación}

Como hemos señalado precedentemente, actualmente se encuentra en proceso de edición la traducción del tercer borrador de discusión de los y Principios y Reglas Transnacionales; esta etapa de traducción no podrá excederse de los próximos tres meses, habida cuenta que la agenda de ALI-UNIDROIT prevé que para mayo del 2003 se realice la próxima Conferencia de evaluación del nuevo proyecto de discusión que se viene siendo ya elaborado por los autores del proyecto de Principios y Reglas; y a fin de poder participar más cercanamente de dicho proyecto, y realizar adecuadamente nuestra labor de colaboradores extranjeros del proyecto, requerimos no solamente asistir a las próximas reuniones que sobre la materia se realicen, sino, sobre todo, contar con un texto que nos sirva de guía y base para seguir el curso de las discusiones que se realicen sobre este proyecto.

Creemos importante, por ejemplo, destacar en este sentido la labor que viene realizando el Instituto Mexicano de Derecho Uniforme, que organizó la reunión llevada a cabo en febrero pasado en México D.F. Esta importante institución viene incentivando la colaboración de los investigadores de habla hispana y, merced a su iniciativa estamos próximos a colaborar en la obra colectiva que sobre la materia se viene preparando.

25 Antonio Gidi, «A presentaçao ao Projeto às Normas Trasnacionais de Processo Civil»; (en sus versiones en portugués y español); Op. cit. 
Por nuestra parte, creemos que nuestra labor de difusión se podrá enriquecer con la organización de una reunión en Lima, Perú, a fin que se de a conocer el proyecto oficialmente, y donde sus autores puedan exponer directamente a los operadores jurídicos peruanos, los fundamentos, desarrollo y actual estado de elaboración de este importante proyecto.

Tenemos como tarea pendiente, sensibilizar al Estado peruano, y a sus autoridades a fin que finalmente se adhieran a UNIDROIT, y ratificar su Estatuto. Hemos iniciado ya las gestiones encaminadas a dicho fin, para lo cual tuvimos la oportunidad de reunir en Lima el 14 de junio del presente año a un importante grupo de juristas peruanos, a los que les expusimos la importancia de esta adhesión. Nuestra labor en este sentido continua, $y$ hemos logrado el compromiso de los profesores con quienes nos reunimos de difundir ante las autoridades nacionales y gestionar dentro de sus posibilidades- esta adhesión.

\section{Futuro cercano y mediato}

El futuro cercano de los Principios y Reglas del Proceso Civil Transnacional se encuadra en su mayor difusión, con la finalidad de ir ganando adeptos a esta noble causa, a fin de poder recoger la mayor cantidad de iniciativas, apreciaciones, comentarios, aportes y sugerencias a fin de enriquecerlo en aras de nuestra propia Comunidad Internacional en el futuro cercano y, con ello, que los operadores jurídicos (investigadores, abogados en ejercicio y miembros de la Judicatura), puedan conocer y manifestar sus apreciaciones y criticas de lo ya trabajado por los autores principales del Proyecto, el Prof. G. C. Hazard y el Prof. M. Taruffo, y con la importante asistencia del Prof. Antonio Gidi, Associate Reporter.

Creemos con plena convicción que la difusión de este importante Proyecto debe iniciarse en las aulas universitarias, deberíamos ponernos como meta cada uno de los colaboradores de este proyecto iniciar su difusión en nuestro entorno académico, pretendiendo por lo menos dar cuenta inicial ante nuestros discípulos de la existencia de este proyecto, para luego incentivar en cada una de nuestras Escuelas de Derecho su estudio, investigación y difusión como parte integrante de un curso que desarrolle los conceptos elementales del Derecho Procesal Transnacional. Es esta, pues, la tarea que tenemos los profesores universitarios a través de la enseñanza del Derecho procesal y su teoría científica, donde, reitero no debiéramos 
limitarnos al ámbito local, sino ser capaces de dar un paso adelante y permitirnos ingresar al estudio del Derecho Procesal Internacional, para lo cual este Proyecto resulta un pionero esfuerzo de notables especialistas.

Como consecuencia del accionar antes señalado podemos avizorar que el futuro cercano del Proyecto de Principios y Reglas pueda ser accesible no solo a los actuales operadores jurídicos, sino y sobre todo a los futuros operadores del derechos, quienes deberían ya al inicio de sus actividades profesionales contar con este instrumento internacional del Derecho Procesal Internacional.

El futuro mediato de este proyecto será la adecuada implementación que los Estados adopten respecto de los principios y reglas en cada una de sus legislaciones. Creemos que esta difícil tarea no va a tener un resultado inminente, puesto que para lograr la adecuación de los principios y reglas en las diversas legislaciones nacionales deberá de transcurrir mucho tiempo, puesto que una modificación de tal naturaleza no solamente requiere del trabajo de los investigadores jurídicos, sino también de la voluntad política de los diferentes gobiernos de adecuar sus legislaciones a la nueva perspectiva del Derecho Procesal Civil Internacional.

Roma, julio del 2002 